\title{
Entrevista a José Carlos Alarcón Arévalo, Director General de Comunicación Social de la Junta de Andalucía
}

\section{«Para las TV locales el cable será una de las vías más importantes de expansión y penetración»}

«El decreto de regulación de las televisiones locales por ondas terrestres se encargará de la concesión de las licencias» «La televisión local tiene cabida como MCS porque está en lo cercano, con mensajes próximos a la vida cotidiana de los ciudadanos»

\section{Rosa Rodríguez Cárcela}

Secretaria de la Asociación Universitaria Comunicación y Cultura, investigadora y periodista de la Consejería de Cultura

José Carlos Alarcón Arévalo es el director general de Comunicación Social de la Junta de Andalucía. Anteriormente ocupó la jefatura del Servicio de Coordinación Informática de la Consejería de la Presidencia. De profesión es ingeniero de Telecomunicaciones y funcionario del Cuerpo Superior Facultativo de Tecnologías de la Información. Nacido en Madrid, aunque su familia es andaluza, tiene dos hijos y es el responsable de las comunicaciones en Andalucía, de radio y televisión, con las funciones de regulación (desarrollo normativo), coordinación e inversión (infraestructuras y contenidos). Próximamente se publicará oficialmente el Decreto de Regulación del Régimen Jurídico de las Televisiones Locales por Ondas Terrestres.

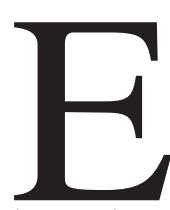

1 titular de la Dirección General de Comunicación Social señala que sus dos grandes áreas competenciales son la comunicación institucional (publicidad, identidad corporativa y comunicación, «desde un punto de vista más empresarial que informativo») y las telecomunicaciones (radiodifusión en ondas métricas de Frecuencia Modulada y televisiones locales por ondas). 
«Adicionalmente tenemos las telecomunicaciones por cable, con la determinación de demarcaciones, y las telecomunicaciones en general, a través de la presencia de la Dirección General en el Consejo de Administración de la Sociedad Andaluza para el Desarrollo de las Telecomunicaciones (Sandetel), con la cual estamos desarrollando la Red Corporativa de Telecomunicaciones de la Junta y la creación de servicios de valor añadido en las telecomunicaciones y el multimedia», aclara Alarcón.

- La DGCS tiene competencias directas en la concesión para la instalación y funcionamiento de radios de FM, a personas físicas o jurídicas, así como de radios municipales. ¿Cuáles son los criterios para la concesión de estas emisoras?

Estamos en proceso de revisión. La Junta tiene la competencia de concesión y posteriormente de supervisión de dicha concesión. Como se ha producido una revisión del Plan Técnico Nacional, hay unas frecuencias disponibles adicionales y hemos ido a un concurso de concesión. En esa concesión de frecuencias -que sólo han sido veintiséis de las cuarenta y dos solicitadas- la Junta no está conforme con los criterios que ha utilizado el Ministerio de Fomento, porque hemos visto que el criterio ha sido muy restrictivo en nuestra comunidad autónoma, mientras que en otras regiones el espectro es más flexible. Tenemos puesto un recurso contencioso administrativo para reclamar la concesión de una serie de frecuencias adicionales que serían viables en Andalucía.

Estamos trabajando y refundiendo, antes de proceder a las nuevas concesiones, en un decreto los criterios a seguir en las concesiones. Como novedades el decreto regulador, revisará los criterios de transferencias de titularidad de las emisoras y el esquema y proceso de revisión, agilizará los procedimientos -competencia compartida con la Administración Central, con la gestión del espacio radioeléctrico-. En el caso de las emisoras municipales, la gestión es más tardía, debido a la implicación de las corporaciones locales.

cía?

- ¿Cuántas radios locales de FM funcionan legalmente en Andalu-

De emisoras municipales, con diferentes estadios de concesiones, unas definitivas y otras en proceso de tramitación, existen 198. Tienen concesión definitiva aproximadamente unas treinta y ocho. De emisoras privadas 
funcionan 136. En cuanto a las emisoras comerciales de FM previstas que se autoricen este año en Andalucía, tal y como he señalado anteriormente, en función de la ampliación del Plan Técnico Nacional, sólo se han concedido veintiséis emisoras, frente a las cuarenta y dos solicitadas por la Junta.

- Desde hace unos años se está produciendo en Andalucía un auge de las televisiones locales, tanto privadas como municipales. ¿Qué opinión le merecen las mismas?.

La Ley de Televisión Local por Ondas Terrestres prevé que en cada término municipal puede haber, como máximo, dos emisoras, una de carácter público y otro privado. Dentro de este marco legal, tenemos muy avanzado el Decreto de Regulación del Régimen Jurídico de las Televisiones Locales por Ondas Terrestres, que se publicará próximamente y se encargará de la concesión de la licencias.

La televisión local tiene una cabida como medio de comunicación social, porque está en lo cercano. Hay una buena receptividad de estos mensajes, muy próximos a la vida cotidiana de los ciudadanos. Es muy característico el comentario «iCaramba, te vi ayer en la televisión!». Existe un espacio como medio de comunicación y de viabilidad para su sostenimiento. Nuestra intención es regular este tema cuanto antes. Mientras no vayamos a la regulación, como todavía no existen concesiones, hay una situación ambigua, donde funcionan más canales de los autorizados por ley. Para las televisiones locales una de las vías de expansión y penetración importante va a ser el cable, ya que está muy vinculado a lo local.

- Cuando se aplique el Decreto de Regulación de las Televisiones Locales ello va a suponer la desaparición de algunas de ellas, especialmente las de ámbito privado.

Evidentemente, ya que la ley establece que el ámbito de difusión o cobertura es de un solo canal privado por término municipal. El proceso a seguir será el que las televisiones locales que están operando actualmente tendrán que presentarse a un concurso público, donde se valorarán los proyectos y sólo se concederá una por término municipal.

- ¿Cuántas televisiones locales funcionan y están registradas por la Junta de Andalucía?

La cuantificación de las emisoras de televisión local es más complicado que en las radios de FM. Están emitiendo televisiones, pero existen algunas en situación de alegalidad y otras de cuasi ilegalidad. Lo importante 
es cerrar el marco normativo y, cuando haya concesiones, sabremos las que hay oficialmente. Los datos que tenemos, de septiembre de 1997, señalan que hay veintitrés emisoras de televisión local municipales y noventa y cinco privadas. Probablemente emitiendo de manera continua existan menos.

En Andalucía son cincuenta y cinco el número de municipios que disponen de televisión local. Por provincias, las que tienen mayor número de TV son Sevilla, Málaga, Cádiz y Almería, zonas urbanas y costeras donde confluyen grandes concentraciones de población. Como media podemos decir que en la mayoría de los municipios con una población superior a los 50.000 habitantes tienen televisión local. Por comunidades autónomas, las más activas en iniciativas de TV local son Andalucía y Cataluña. Yo creo que es un fenómeno bueno. Al margen del crecimiento de la televisión local en sí misma, toda esta expansión de las comunicaciones plantea unas posibilidades enormes para nuestra industria audiovisual, que se están concretando en iniciativas concretas como la puesta en marcha del segundo canal de la RTVA y el proyecto Andalucía Digital.

- La industria audiovisual es un buen recurso para explotar en Andalucía. ¿Existen previsiones sobre los puestos de trabajo que puede generar en un futuro próximo?.

El Instituto de Fomento de Andalucía (IFA) ha elaborado un estudio sobre los puestos de trabajo que puede crear esta industria incipiente en Andalucía y las perspectivas son buenas. Actualmente el sector está un poco atomizado, pero existe una enorme oportunidad para consolidarla competitivamente. El producto cultural andaluz tiene una magnífica receptividad en el resto de España, en Europa y en el mercado iberoamericano.

- ¿En qué consiste el proyecto Andalucía Digital?

Va en la línea de los proyectos europeos Media Parks, que pretende situar en un único contexto, de forma interrelacionada, a todos aquellos organismos y entidades que producen contenidos, a los operadores, a los fabricantes y a la Universidad para actuaciones de investigación. En este proyecto participa la RTVA y Sandetel, encargada esta última de gestionar las redes de telecomunicaciones del sector público andaluz y de impulsar proyectos de servicios de valor añadido y multimedia.

- La actuaciones de la Dirección General de Comunicación Social en materia de telecomunicaciones por cable se han centrado en el establecimiento de demarcaciones -del ámbito territorial donde se prestará el servicio por cable- y para ello se han tenido en cuenta dos 
premisas, por una parte un límite mínimo de $\mathbf{5 0 . 0 0 0}$ habitantes y otro máximo de 2.000.000. El resultado final ha sido la creación de cuatro grandes demarcaciones: una primera incluye las provincias de Almería, Granada y Jaén; una segunda que comprende Córdoba y Málaga; la provincia de Sevilla es la tercera; y la cuarta engloba Huelva y Cádiz.

Lo que ha realizado la Junta de Andalucía ha sido fundamentalmente impulsar la creación de cuatro grandes demarcaciones en Andalucía, ya que la Ley del Cable establece que las prestaciones del servicio se realice en demarcaciones. Nuestra concepción ha sido que era necesario hacer demarcaciones amplias que conjugaran grandes núcleos de población con otros menores, al objeto de conseguir la máxima extensión del servicio en el menor periodo de tiempo. Una demarcaciones adaptadas a la sociedad de la información del siglo XXI. En cada demarcación se ha definido que haya dos operadores, elegidos mediante concurso público. Este año comenzarán a prestar sus servicios en las grandes capitales y núcleos de población. La Junta se encargará de la supervisión del proceso de despliegue. Las inversiones previstas en los próximos diez años superan los 240.000 millones de pesetas», aclara José Carlos Alarcón.

- Cambiando de ámbito, otra de las grandes competencias de esta Dirección General es la coordinación y el seguimiento del Manual de Identidad Corporativa de la Junta de Andalucía. El año pasado la Administración Autónoma decidió implantar un nuevo manual, tras doce años de vigencia del anterior. ¿Cuáles han sido las transformaciones más significativas aplicadas?

La Junta hace doce años era la quinta parte de lo que es ahora, lo que quiere decir que el anterior manual era imposible que plasmara toda la complejidad que tiene ahora la Administración. Por su parte, los medios de comunicación han evolucionado de una manera vertiginosa y los criterios de imagen y soporte han cambiado. Ello nos llevó a la necesidad de actualización. Cuando lo hicimos teníamos dos previsiones: en primer lugar, los símbolos institucionales -el escudo-, que lo teníamos que mantener por imperativos legales; por otro lado, existían multitud de otras aplicaciones audiovisuales en medios escritos, donde era más complicada la utilización del escudo. Ello nos llevó a plantear la posibilidad de contar con otro símbolo complementario que fuera más versátil para poder utilizarlo en numerosos soportes. A la hora de elaborar este símbolo complementario, pensa- 
mos en reservar el escudo para un uso más institucional y el nuevo símbolo para el resto de actuaciones. Existe, pues, un nuevo símbolo, pero el anterior escudo permanece, exclusivamente para una utilización institucional. El nuevo símbolo ha tratado de ser sencillo en su concepción, versátil, fácil de utilizar y de transmitir una imagen de modernidad, de la Andalucía de hoy que se expande también hacia afuera.

- Cuando se presentó el nuevo Manual de Identidad Corporativa se realizaron críticas, sobre todo referidas a posibles plagios con otros diseños que estaban en el mercado. ¿Qué opina al respecto?

Esto es absolutamente falso. La mejor demostración de que no ha existido plagio es que cuando tuvimos el primer esbozo del diseño iniciamos los trámites de su registro en la Propiedad Industrial. Si hubiera habido plagio, lo normal es que alguien hubiera recurrido, cosa que no ha ocurrido. La Oficina de Patentes y Marcas decretó la concesión del logotipo, con fecha de 20 de enero de 1998. Es decir, que está registrado como patente de la Junta de Andalucía.

- La estructura del mercado de la comunicación se va decantando hacia las telecomunicaciones. Es un sector importante, donde las previsiones para la creación de nuevos puestos de trabajo son positivas. ¿Qué papel juega la Junta de Andalucía al respecto?

La Administración tiene un papel de impulso y fomento. Hemos impulsado las telecomunicaciones por cable y ahora, en su desarrollo, se van a crear puestos de trabajo. Esto es importante. Las previsiones de empleo, directo e indirecto, del cable se cifran en 15.000 puestos para los próximo diez años. Telefónica, por su parte, ya sostiene un volumen importante de puestos de trabajo y va a crear más. Por su parte, las televisiones locales son también una vía de creación de empleo.

En lo que se refiere a las actuaciones públicas, la vía más directa de creación de empleo se centra fundamentalmente en la puesta en marcha del segundo canal de la RTVA. La idea básica es que Canal Sur tiene un sentido de servicio público y debe atender a un amplio sector de ciudadanos, con gustos y demandas diferentes. Con el segundo canal se pretende dar cabida a esos segmentos de público que ahora no pueden atenderse, porque existe una oferta televisiva muy generalista. Hablamos de un público esencialmente urbano, joven y con un nivel cultural medio o medio-alto. 
ANEXOS:

GRÁFICOS DE TELECOMUNICACIONES POR CABLE EN ANDALUCÍA (FEBRERO 1998) Y BORRADOR DE DECRETO DE REGULACIÓN DEL RÉGIMEN JURÍDICO DE LAS TELEVISIONES LOCALES POR ONDAS TERRESTRES (ANDALUCÍA)

\section{Las Telecomunicaciones por Cable en Andalucía}



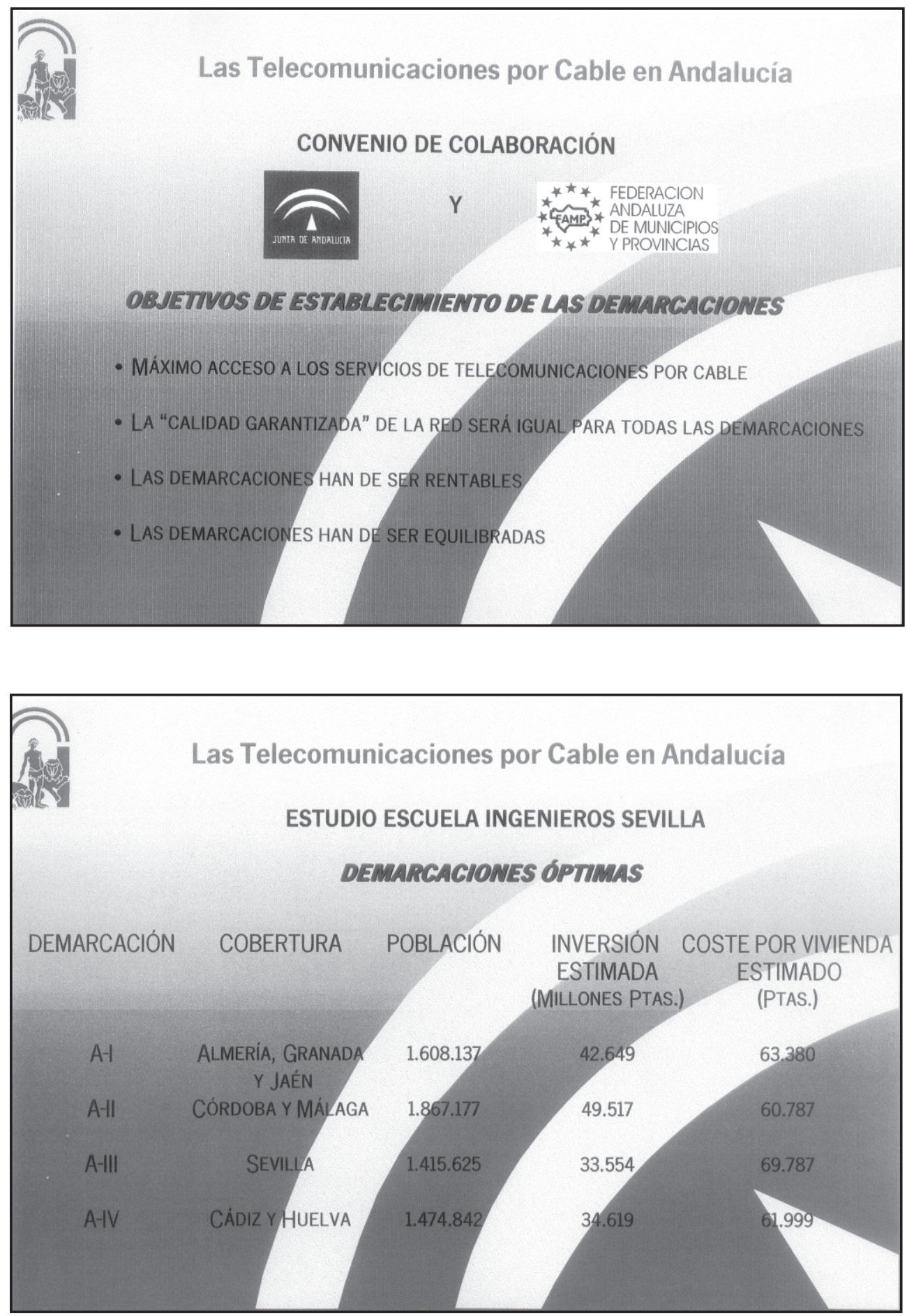


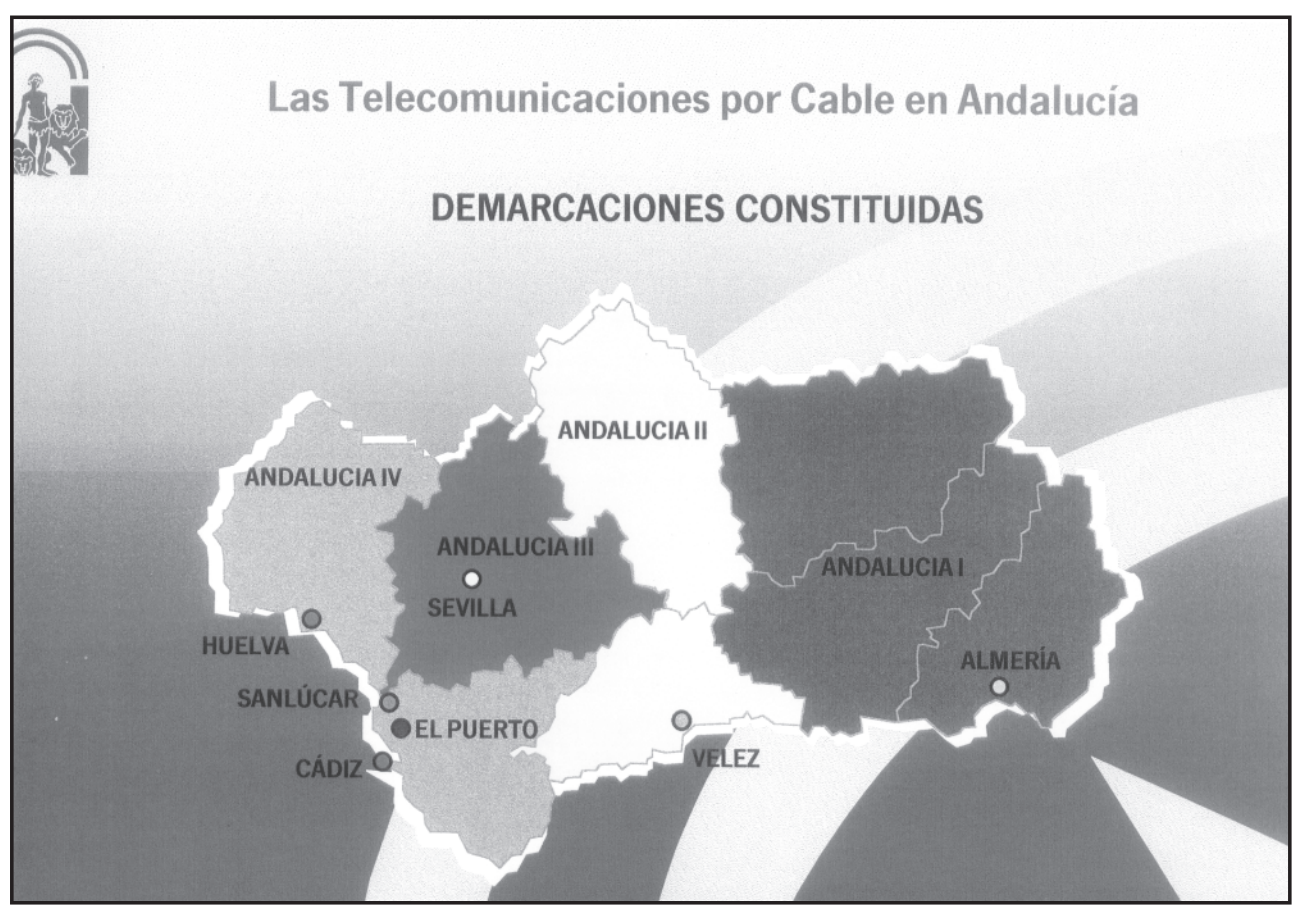

\section{Las Telecomunicaciones por Cable en Andalucia}

\section{COBERTURA DE LAS DEMARCACIONES CONSTITUIDAS}

DEMARCACIÓN NN MUNICIPIOS \% MUNICIPIOS POBLACIÓN \% POBLACIÓN INVERSIÓN

CUBIERTOS CUBIERTOS CUBIERTA CUBIERTA MINIMA

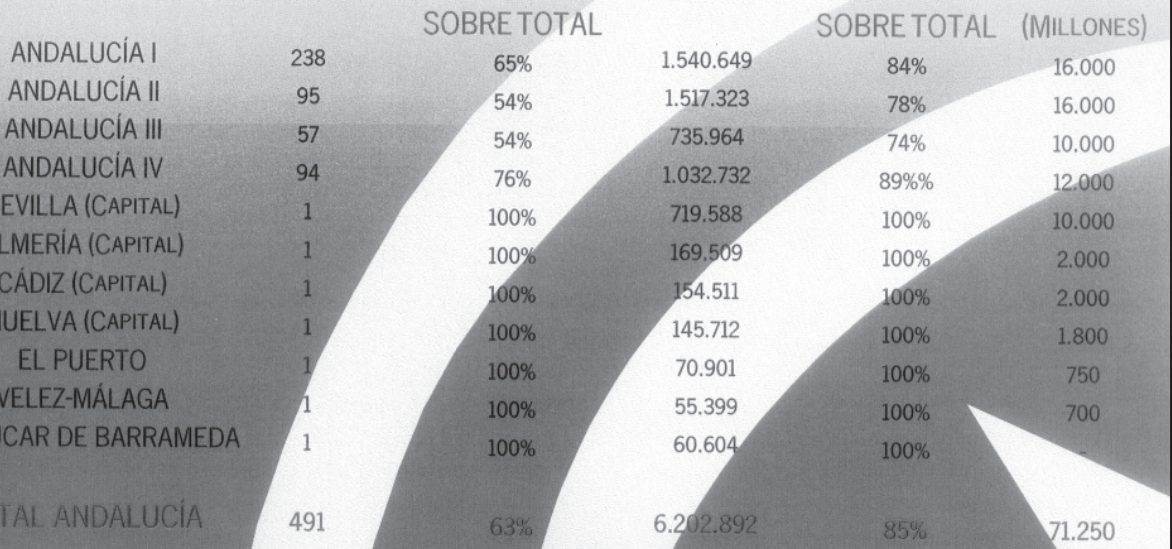




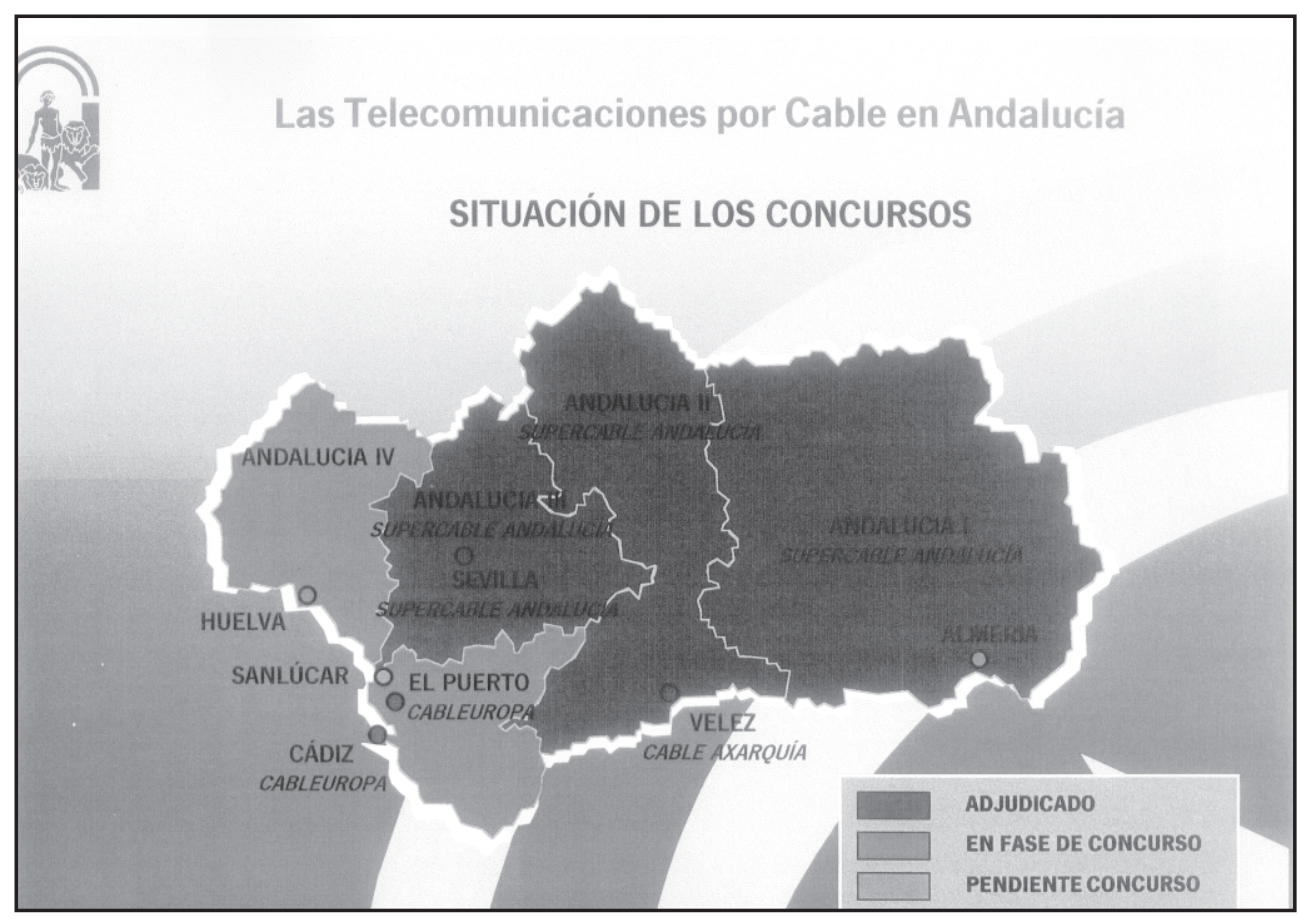

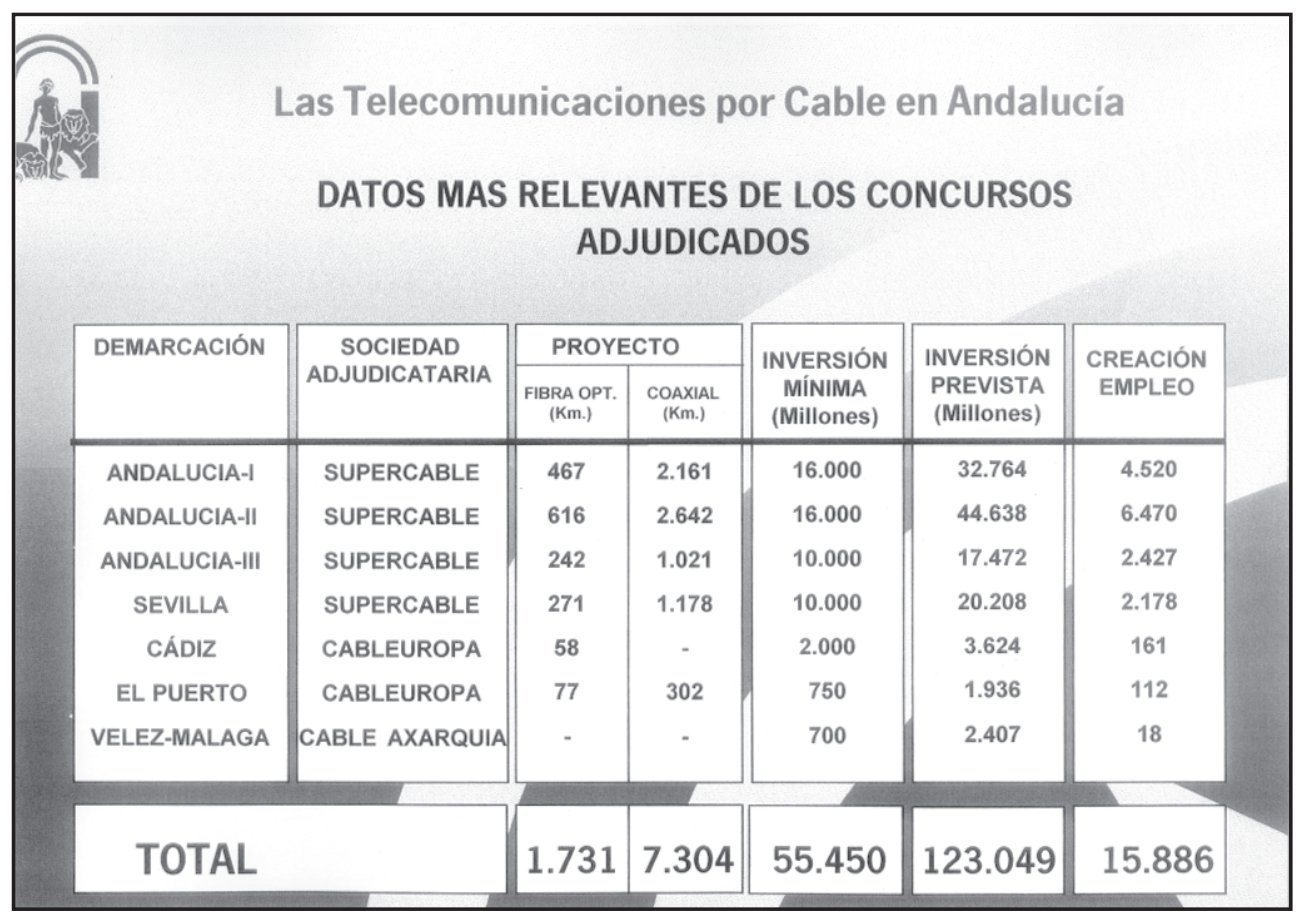




\section{Las Telecomunicaciones por Cable en Andalucía}

\section{OFERTA DE SERVICIOS}

\section{Senvicios de Difusion e Interactivos TV}

- Servicio básico

- PAgO POR VISIÓN (PPV)

- Canales Premium

- Casi Video Bajo demanda (NVOD)

- Canales Audio

- VÍDEo BAJO DEMANDA (VOD)

Senvicios Finales

- Telefonía Básica (POT)

- Red Digital de SERVICIOS INTEgRados (RDSI)

- SERVICIOS AVANZADOS DE TELEFONIA

Servicios de Velor Airadido

- Correo electrónico

- INTERNET / INTRANET / EXTRANET

- VIDEOCONFERENCIA

- VIDEOJUEGOS

Servicio Portador de Jelecorrasuvicuciones

- Alquiler pe Circuitos pigitales y analógicos

- X.25

- Frame Relay

- ATM

REDEs PRIVADAs VIRTUales (RPV) - CENTREX - CENTREX 


\section{BORRADOR DE DECRETO DE REGULACIÓN DEL RÉGIMEN JURÍDICO DE LAS TELEVISIONES LOCALES POR ONDAS TERRESTRES}

El artículo 16 del Estatuto de Autonomía para Andalucía, establece que corresponde a la Comunidad Autónoma, en el marco de las normas básicas del Estado, el desarrollo legislativo y la ejecución del régimen de radiodifusión y televisión en los términos y casos establecidos en la Ley que regula el Estatuto jurídico de la Radio y Televisión.

El presente Decreto tiene por objeto la regulación del régimen jurídico de la televisión local por ondas terrestres en la Comunidad Autónoma de Andalucía, al que le es también de aplicación la regulación estatal contenida en la ley 31/1987, de 18 de diciembre, de Ordenación de las Telecomunicaciones y la ley 41/ 1995, de 22 de diciembre, de Televisión Local por Ondas Terrestres.

La necesidad normativa viene impuesta al representar actualmente las televisiones locales por ondas terrestres una realidad que ha surgido como expresión de la iniciativa y la diversidad de manifestaciones culturales en Andalucía y que precisa la culminación del marco normativo que permita la consolidación de los proyectos de comunicación local y su contribución al desarrollo del sector audiovisual de Andalucía.

En su virtud, a propuesta del Consejero de la Presidencia, de acuerdo con el Consejo Consultivo, y previa deliberación del Consejo de Gobierno en su reunión del día de 1998.

\section{DISPONGO}

\section{CAPÍTULO I: DISPOSICIONES GENERALES}

\section{Artículo 1. Objeto}

El presente decreto tiene por objeto la regulación del régimen jurídico del servicio público de la televisión local por ondas terrestres en Andalucía.

Artículo 2. Concepto y régimen jurídico

1.- La Televisión local por ondas terrestres consiste en la emisión o transmisión de imágenes y sonido, no permanentes, dentro del ámbito señalado en el artículo 3, dirigidas al público, sin contraprestación económica directa, mediante ondas electromagnéticas, propagadas desde una estación transmisora terrestre.

2.- La televisión local por ondas terrestres es un servicio público. Para la prestación del servicio de televisión local por ondas terrestres será necesario disponer de concesión administrativa. 
Artículo 3. Ámbito territorial de cobertura

1.- El ámbito territorial de cobertura de cada televisión local por ondas terrestres queda delimitado por el núcleo urbano principal de población del Municipio correspondiente.

2.- El ámbito de cobertura podrá alcanzar también otros núcleos de población del mismo Municipio de conformidad con lo establecido en el artículo 3.2 de a Ley 41/1995, de 22 de diciembre, de televisión local por ondas terrestres.

3.- Excepcionalmente, y en el supuesto previsto en el artículo 6 de este Decreto, se podrán autorizar coberturas que superen el estricto ámbito territorial de una televisión local por ondas terrestres mediante la emisión en cadena.

Artículo 4. Tipo y número de concesiones.

1.- Las emisoras de televisión local por ondas terrestres objeto de la concesión, atendiendo a la titularidad de su gestión, serán de dos tipos: municipales y privadas.

2.- El número de concesiones se fija en una por cada ámbito territorial de cobertura del servicio. No obstante, podrá otorgarse un máximo de dos concesiones en un sólo ámbito territorial en el supuesto establecido en el apartado 5 de este artículo.

3.- La concesión que con carácter general se establezca por cada ámbito territorial será preferentemente municipal.

4.- Cuando el Municipio no haga uso de la opción preferencial establecida en el apartado anterior, el Consejero de la Presidencia podrá determinar que la gestión de la prestación del servicio objeto de la concesión sea de titularidad privada.

5.- Asimismo, aún existiendo una concesión municipal, el Consejero de la Presidencia podrá determinar el otorgamiento de una segunda concesión de gestión para la prestación del servicio, siempre de titularidad privada, atendiendo a (causas objetivas, tales como) la disponibilidad del espectro radioeléctrico o a la viabilidad económica de las emisoras.

Artículo 5. Principios inspiradores

La prestación del servicio de televisión local por ondas terrestres se inspirará en los siguientes principios:

1.- La objetividad, la veracidad y la imparcialidad de las informaciones. 
2.- La separación entre informaciones y opiniones, la identificación de quienes sustentan estas últimas y su libre expresión con los límites previstos en el apartado 4 del artículo 20 de la Constitución Española.

3.- El respeto al pluralismo político, religioso, social y cultural.

4.- El respeto del honor, a la intimidad personal y familiar, a la propia imagen, y a todos los derechos y libertades reconocidas por la Constitución.

5.- La protección de la juventud y de la infancia, de acuerdo con lo que establecen el capítulo IV de la Ley 25/1994, de 12 de julio, por la que se incorpora al ordenamiento jurídico la Directiva 89/552/CEE, sobre la coordinación de disposiciones legales, reglamentarias y administrativas de los Estados miembros relativos al ejercicio de actividades de radiodifusión televisiva.

6.- El respeto al derecho de igualdad reconocido en el artículo 14 de la Constitución.

7.- El fomento y la defensa de la cultura e intereses locales, así como la promoción de la convivencia, impulsando, a este efecto, la participación en el medio de los grupos sociales del ámbito territorial de cobertura correspondiente.

8.- El fomento de la conciencia de identidad andaluza a través de la difusión de los valores culturales y lingüísticos del pueblo andaluz en toda su riqueza y variedad.

9.- La protección a la dignidad y a los derechos de la mujer, y la promoción efectiva de la igualdad, sin distinción de sexo.

10.- El fomento de comportamientos tendentes a la correcta utilización de los recursos naturales y a la preservación del medio ambiente.

Artículo 6. Emisiones en cadena

1.- De conformidad con el artículo 7 de la ley 41/1995, de 22 de diciembre, las televisiones locales por ondas terrestres no podrán emitir o formar parte de una cadena de televisión.

2.- No obstante, el Consejero de la Presidencia, previo informe de la Dirección General de Comunicación Social, y con la conformidad de los plenos de los 
Ayuntamientos de los municipios afectados, podrá autorizar excepcionalmente emisiones en cadena atendiendo a características de proximidad territorial y de identidad social y cultural de dichos municipios.

3.- La solicitud de autorización para las emisiones en cadena deberá ser formalizada por los titulares de la gestión del servicio ante la Consejería de la Presidencia, debiendo aportar, como mínimo, los siguientes datos y documentos:

- Televisiones locales que deseen realizar las emisiones.

- Características de la programación a emitir en cadena: temática, origen de la producción y porcentaje del tiempo de emisión.

- Acuerdo de conformidad de los Plenos Municipales.

4.- Para la autorización, en su caso, se valorará preferentemente que la programación a emitir en cadena sea de producción conjunta de las televisiones implicadas o realizada por terceros en Andalucía.

\section{CAPÍTULO II: DE LA GESTIÓN DEL SERVICIO}

Artículo 7. Concesiones

1.- Corresponde al Consejo de Gobierno, a propuesta del Consejero de la Presidencia, el otorgamiento de las concesiones para la prestación del servicio de televisión local por ondas terrestres, tanto si la gestión es municipal como si es privada.

En este último caso, la concesión se otorgará por el procedimiento de concurso público.

2.- No podrá otorgarse ninguna concesión sin que previamente se haya obtenido de los órganos competentes la reserva provisional de frecuencia y se señalen las demás características técnicas, en los términos del artículo 10 de la Ley de Televisión Local por ondas terrestres.

La concesión se ajustará a la frecuencia, potencia y demás características técnicas que dichos órganos determinen.

3.- La concesión será intransferible. Los actos o negocios jurídicos que comporten la transmisión, disposición o gravamen de las acciones o participaciones de la sociedad concesionaria deberán ser autorizados por el Consejero de la Presidencia, previa solicitud de las partes interesadas. Será requisito constitutivo de los actos 
y negocios jurídicos mencionados, su formalización mediante documento autorizado por federativo público, quién no intervendrá o autorizará documento alguno sin que se acredite la preceptiva autorización administrativa.

Artículo 8. Gestión municipal del servicio

1.- Los Municipios titulares de una concesión de servicio público de televisión local por ondas terrestres deberán gestionarla directamente, por cualquiera de las formas previstas en el artículo 85.3 de la Ley 7/1985, de 2 de abril, reguladora de las Bases de Régimen Local.

2.- La financiación del servicio se realizará de conformidad con la normativa vigente.

3.- El Pleno del Ayuntamiento concesionario ejercerá el control de la gestión del servicio, velando por el respeto a los principios relacionados en el artículo 5 del presente Decreto, así como por el cumplimiento de las restantes obligaciones asumidas como concesionario, sin perjuicio de las competencias inspectoras y sancionadoras de la Administración de la Junta de Andalucía.

Artículo 9. Gestión privada del servicio

1.- Las personas naturales o jurídicas privadas, para acceder a la titularidad de una concesión del servicio público de televisión local por ondas terrestres, deben reunir los siguientes requisitos:

a) tener la nacionalidad española o de cualquier otro Estado miembro de la Unión Europea en los términos establecidos en el artículo 13.2 de la Ley 41/1995, de 22 de diciembre.

b) tener capacidad para contratar con la Administración de conformidad con lo dispuesto en el artículo 15 de la Ley 13/1995, de 18 de mayo, de Contratos de las Administraciones Públicas, y no hallarse incurso en ninguna de las prohibiciones de contratar previstas en el artículo 20 de la citada Ley.

c) además, cuando se trate de sociedades:

1. Su objeto social deberá incluir, necesariamente, la gestión indirecta del servicio de televisión local por ondas terrestres.

2. Para aquellas sociedades que tengan todo o parte de su capital social dividido en acciones, éstas deberán ser nominativas.

3. La participación extranjera en su capital no podrá superar, directa o indirectamente, el veinticinco por ciento de su cuantía. A tal efecto, se entenderán extranjeras las personas que no tengan la nacionalidad de un Estado miembro de la Unión Europea. 
4. Deberá tener su domicilio social y su centro principal de actividad en el ámbito territorial de la emisora objeto de la concesión.

5. No podrá ser participada mayoritariamente, de forma directa o indirecta, por ningún accionista que a su vez participe de dicha forma en otra sociedad concesionaria.

6. Deberá tener, en el momento de la solicitud para participar en la fase de adjudicación, el capital totalmente suscrito y desembolsado, al menos, en un $50 \%$. Al tiempo de otorgarse la concesión definitiva, deberá acreditarse haber sido desembolsada la totalidad del capital suscrito.

2.- No podrá ser titular de una concesión o participar en un porcentaje superior al $10 \%$ en una sociedad concesionaria:

a) aquella persona que, a su vez, hubiera sido titular de una concesión o participado en un porcentaje superior al $10 \%$ en una sociedad concesionaria cuya concesión se hubiera extinguido como consecuencia de infracción calificada como muy grave por la normativa aplicable en la materia.

b) aquella persona que hubiera sido sancionada, mediante Resolución administrativa firme, como responsable de la comisión de una infracción muy grave por la prestación del servicio de televisión local por ondas terrestres sin la correspondiente concesión, o que participara en un porcentaje superior al $10 \%$ en una sociedad que hubiera sido sancionada por la comisión de dicha infracción.

3.- En ningún caso podrá ser concesionario el que sea titular de otra concesión de televisión local por ondas terrestres o participe mayoritariamente, de forma directa o indirecta, en otra sociedad concesionaria.

\section{CAPÍTULO III: DEL OTORGAMIENTO DE LAS CONCESIONES}

Artículo 10. Procedimiento de concesión

El procedimiento para el otorgamiento de concesiones del servicio de televisión local por ondas terrestres se desarrollará en dos fases sucesivas, una de solicitud y otra de adjudicación.

\section{Artículo 11. Fase de solicitud}

Los municipios y las personas naturales o jurídicas privadas interesadas en la gestión de este servicio, deberán presentar sus solicitudes en la forma y plazo que se establezca en las convocatorias que a tal efecto realice el Consejero de la Presidencia, que serán publicadas en el Boletín Oficial de la Junta de Andalucía. 
Las solicitudes para participar en esta fase serán dirigidas a la Dirección General de Comunicación Social, debiendo acompañar la documentación que se indica en el Anexo I de este Decreto.

Artículo 12. Reserva de frecuencia

Concluido el plazo de presentación de solicitudes, la Consejería de la Presidencia planificará las necesidades y recabará de los órganos competentes la determinación de la frecuencia, potencia y otras características técnicas de las emisoras locales, o, en su caso, la declaración de su invariabilidad técnica.

Artículo 13. Fase de adjudicación

1.- Recibida la Resolución del órgano competente declarando la reserva provisional de frecuencia, el Consejero de la Presidencia realizará una nueva convocatoria para la adjudicación de concesiones, de acuerdo con los términos del artículo 4 de este Decreto, que será publicada en el Boletín Oficial de la Junta de Andalucía.

Las solicitudes para participar en esta fase serán dirigidas a la Dirección General de Comunicación Social, debiendo acompañar la documentación que se indica en el Anexo II de este Decreto.

2.- Esta fase de adjudicación tendrá carácter de concurso público para las personas naturales y jurídicas privadas interesadas.

3.- En ella sólo podrán participar quienes hubiesen presentado solicitud en la fase anterior.

4.- Cuando se trate de solicitudes de personas físicas o jurídicas privadas, la Dirección General de Comunicación Social requerirá el informe del Ayuntamiento correspondiente al ámbito de cobertura para el que se solicita la concesión, que será de carácter no vinculante.

Transcurridos quince días hábiles desde la recepción por el Ayuntamiento respectivo del citado requerimiento, sin que se haya recibido dicho informe, se proseguirá la tramitación sin necesidad de éste.

\section{Artículo 14. Adjudicación provisional}

1.- Completada la tramitación prevista en los artículos anteriores, el Consejero de la Presidencia, teniendo en cuenta las ofertas presentadas, la viabilidad técnica 
y económica de las mismas, las garantías ofrecidas por los solicitantes para el mejor cumplimiento de los principios inspiradores recogidos en el artículo 5 de este decreto y la observancia de los demás requisitos establecidos en la legislación vigente, elevará al Consejo de Gobierno la propuesta motivada de adjudicación provisional de las concesiones.

2.- El Consejo de Gobierno resolverá la adjudicación provisional de las concesiones, que será publicada en el Boletín Oficial de la Junta de Andalucía y notificada a los interesados.

\section{Artículo 15. Proyecto técnico y ejecución}

1.- El adjudicatorio provisional de la concesión dispondrá, a partir de su publicación en el Boletín Oficial de la Junta de Andalucía, de un plazo máximo de cuatro meses para presentar en la Dirección General de Comunicación Social, el proyecto de las instalaciones suscrito de acuerdo con las normas vigentes y ajustado a las prescripciones contenidas en el acuerdo de adjudicación provisional de la concesión.

2.- Dicho proyecto será remitido al órgano competente para resolver su aprobación o denegación.

3.- Aprobado el proyecto técnico, el adjudicatorio provisional de la concesión dispondrá de un plazo máximo de doce meses para la finalización de las obras e instalaciones correspondientes.

4.- En caso de denegación o propuesta de modificación del proyecto, ésta se notificará al adjudicatorio provisional de la concesión, con indicación de los motivos, al efecto de que presente, en el plazo máximo de dos meses a partir de dicha notificación, un nuevo proyecto técnico subsanando las deficiencias. El plazo utilizado por el adjudicatario provisional para presentar el nuevo proyecto, estará incluido en los doce meses establecido como plazo máximo en el apartado anterior. Toda nueva denegación o propuesta de modificación habrá de ser resuelta en los plazos y términos indicados anteriormente.

5.- Transcurridos los plazos establecidos en los apartados anteriores para la presentación de proyectos o la finalización de las instalaciones sin que estas se hayan materializado, el Consejero de la Presidencia resolverá la pérdida de efectos de la adjudicación provisional, quedando la reserva de frecuencia disponible para una nueva convocatoria. 
6.- Finalizadas las instalaciones e inspeccionadas y aprobadas por el órgano competente, la Dirección General de Comunicación Social levantará el acta de conformidad final.

\section{Artículo 16. Adjudicación definitiva}

1.- Ejecutados los trámites anteriores, el Consejero de la Presidencia elevará al Consejo de Gobierno la propuesta de adjudicación definitiva de la concesión, que será acordada por éste y publicada en el Boletín Oficial de la Junta de Andalucía.

2.- Tras la publicación de la adjudicación definitiva de la concesión, se formalizará el contrato de gestión del servicio público en documento administrativo. Con la firma de dicho documento, el concesionario quedará facultado para la prestación del servicio de televisión local por ondas terrestres, en las condiciones pactadas, con los parámetros técnicos asignados y de acuerdo con la normativa vigente.

Artículo 17. Criterios de adjudicación

1.- El Consejo de Gobierno, al efecto del otorgamiento de la adjudicación provisional a personas naturales y jurídicas, ponderará el grado de concurrencia conjunta en el solicitante de los siguientes aspectos:

a) El interés cultural o educativo del proyecto, valorando esencialmente el fomento de las diferentes manifestaciones de la cultura local y andaluza.

b) La promoción de la diversidad etnográfica y social dentro del ámbito territorial de cobertura, especialmente a través de la participación de los grupos sociales más significativos.

c) La creación de emisoras que realicen su programación en Municipios con población dispersa en núcleos urbanos aislados, cuya puesta en marcha suponga un factor de integración territorial y de conocimiento de los servicios públicos.

d) La viabilidad del proyecto y, también, las garantías de continuidad en la prestación del servicio.

e) La experiencia de los solicitantes en el ejercicio de actividades audiovisuales en el área de televisión, ajustada al mayor cumplimiento de los principios aspiradores establecidos en el artículo 5 de este Decreto.

f) El compromiso de realizar una programación que sobrepase los mínimos establecidos en los artículos 18 y 19.

g) La prestación correcta del servicio, cuando se trata de solicitantes que han sido concesionarios anteriormente. Se entenderá correcta la prestación del servicio cuando el concesionario haya dado cumplimiento a los compromisos concesionales y nunca haya sido sancionado por alteraciones de los parámetros técnicos asignados. 
h) El fomento de la creación de empleo y de la formación ocupacional.

i) Otros que, a la vista de la documentación presentada, sean considerados especialmente relevantes.

2.- De conformidad con la disposición adicional octava de la Ley 13/1995, de 18 de mayo, se podrá señalar en los pliegos de cláusulas administrativas particulares la preferencia en la adjudicación de los contratos para aquellos interesados que, en el momento de la solicitud, tengan en su plantilla un número de trabajadores minusválidos no inferior al $2 \%$, siempre que sus proyectos igualen en sus términos al del más ventajoso desde el punto de vista de los criterios señalados en el párrafo anterior.

\section{CAPÍTULO IV: DE LA PROGRAMACIÓN}

\section{Artículo 18. Tiempo de emisión}

El tiempo mínimo de emisión de programas en las televisiones locales por ondas terrestres será de cuatro horas diarias o de veintiocho horas semanales.

\section{Artículo 19. Producción propia y obras europeas}

1.- El tiempo de emisión de las televisiones locales estará compuesto en un mínimo del 51\% de su duración, necesariamente, por programas de producción propia si bien se podrá considerar hasta un 50\% de esta producción propia, la programación coproducida o la realizada por terceros en Andalucía.

2.- Los conocimientos deberán efectuar las reservas de las obras europeas previstas en la normativa general de aplicación.

Artículo 20. Protección del menor

La programación de las televisiones locales deberá respetar la normativa aplicable a la protección de los menores.

\section{Artículo 21. Publicidad}

1.- La publicidad emitida en las televisiones locales por ondas terrestres deberá respetar la Ley 34/1988, de 11 de noviembre, general de publicidad, y, especialmente, 
en cuanto a publicidad por televisión y patrocinio televisivo, el capítulo III de la Ley 25/1994, de 12 de julio.

2.- El tratamiento publicitario electoral en estas emisoras se regirá por lo dispuesto en la Ley Orgánica 14/1995, de 22 de diciembre, de publicidad electoral en emisoras de televisión local por ondas terrestres.

\section{CAPÍTULO V: DE LA EXPLOTACIÓN}

Artículo 22. Condiciones de explotación

El concesionario queda sujeto a las siguientes obligaciones:

a) explotar directamente el servicio.

b) respetar los parámetros y otras condiciones técnicas de la concesión, así como las especificaciones técnicas y de homologación de los aparatos, equipos y dispositivos utilizados para emitir.

c) garantizar la prestación continuada del servicio, dentro del plazo fijado en la concesión, que no podrá interrumpirse durante más de quince días consecutivos en un año, sin la autorización previa de la Dirección General de Comunicación Social.

d) facilitar las comprobaciones e inspecciones que deba llevar a cabo la Dirección General de Comunicación Social para verificar el cumplimiento de los compromisos, normativa y condiciones técnicas de la concesión.

e) respetar los principios contenidos en el artículo 5 y cumplir las prescripciones establecidas en el artículo 3 y en el capítulo IV del presente Decreto.

f) abonar o, en su caso, resarcir el pago obligado de cuantas cantidades, cualquiera que sea su naturaleza o carácter, se deriven de la prestación del servicio.

g) difundir gratuitamente, con indicación de su origen, los comunicados y avisos de carácter oficial cuando, por su urgencia, importancia e interés público, así lo determine el Gobierno de la Junta de Andalucía o el Gobierno de la Nación.

En circunstancias excepcionales, producidas por situaciones de emergencia, catástrofes locales o generalizadas u otras situaciones similares, el concesionario deberá prestar sus medios técnicos, así como la ayuda y colaboración necesaria a los servicios correspondientes de la Administración Autonómica.

h) notificar a la Dirección General de Comunicación Social el nombramiento del director o responsable de la emisora.

i) solicitar a la Dirección general de Comunicación Social la autorización de los negocios jurídicos a los que se refiere el artículo 7.3 del presente Decreto.

j) presentar a la Dirección General de Comunicación Social antes del 15 de diciembre de cada año, el plan orientativo de programación previsto para el año 
siguiente, con especificación de las horas de emisión y determinación de la programación de producción propia. Cualquier modificación de los aspectos citados tendrá que comunicarse a dicho centro directivo.

Asimismo, en el transcurso de los dos meses siguientes al cierre anual de cada ejercicio, tendrá que presentarse una memoria justificativa de la situación económico-financiera de la emisora.

k) aportar trimestralmente ante la Dirección General de Comunicación Social, la declaración justificativa del cumplimiento de los requisitos de programación y publicidad establecidos en el capítulo IV de este Decreto, y conservar toda la programación emitida durante doce meses, a los efectos de comprobación e inspección.

1) indemnizar los daños y perjuicios ocasionados a terceros o a la propia Administración como consecuencia de la ejecución del contrato concesional, en los términos establecidos en la legislación de contratos públicos.

m) abonar las tasas correspondientes a la realización por la Comunidad Autónoma de Andalucía de las actividades previstas en el presente Decreto, en los términos establecidos en la legislación de aplicación.

n) cumplir las demás obligaciones contractualmente asumidas.

Artículo 23. Duración de la concesión

1.- La duración del contrato concesional será la establecida en la ley 41/ 1995, de 22 de diciembre, de Televisión Local por ondas Terrestres, si bien podrá prorrogarse, previa solicitud del interesado, con tres meses de antelación al vencimiento de la concesión, en los términos establecidos en la citada ley.

2.- A tal efecto, la Dirección General de Comunicación Social podrá requerir al interesado la documentación necesaria para valorar el grado de cumplimiento de las obligaciones y requisitos de la concesión y de la prestación del servicio.

3.- El Consejo de Gobierno resolverá la prórroga de la concesión, a propuesta del Consejero de la Presidencia.

4.- La desestimación de la prórroga no genera el derecho a exigir a la Administración ningún tipo de indemnización, y obliga al concesionario a cesar en la emisión en el plazo máximo de seis meses desde la notificación de la misma. 
Artículo 24. Extinción de la concesión

1.- La concesión se extinguirá por cualquiera de las siguientes causas:

a) Por transcurso del plazo, sin haberse otorgado su renovación.

b) Por incumplimiento sobrevenido de los requisitos esenciales de la misma establecidos en el artículo 25.2. de este Decreto.

c) Por sanción firme, acordada por el órgano competente.

d) Por las causas previstas en la legislación de contratos de las Administraciones Públicas.

e) Por no haber iniciado, sin causa justificada, las emisiones dentro del plazo fijado en la concesión.

f) Por suspensión injustificada de las emisiones durante más de quince días consecutivos en el plazo de un año.

2.- Extinguida la concesión, la frecuencia asignada quedará disponible para una nueva convocatoria.

\section{CAPÍTULO VI: RÉGIMEN SANCIONADOR}

Artículo 25. Infracciones y sanciones

1.- Sin perjuicio de los efectos jurídicos y responsabilidades que pudiera contraer el concesionario como consecuencia del incumplimiento de la legislación de contratos de las administraciones públicas, el régimen sancionador será el previsto en el artículo 16 de la Ley 41/1995, de 22 de diciembre, de Televisión Local por Ondas Terrestres.

2.- Se entenderán condiciones esenciales de la concesión a los efectos previstos en el artículo 33.2 e) de la Ley 31/1987, de 18 de diciembre, de Ordenación de las Telecomunicaciones, las reflejadas en los apartados a), b), c), d), e) y m) del artículo 22 del presente Decreto.

Artículo 26. Competencia sancionadora de:

1.- El ejercicio de la potestad sancionadora en esta materia correspon-

a) Al Consejero de la Presidencia de la Junta de Andalucía, si se trata de infracciones muy graves cometidas por los titulares de la concesión. La renovación 
definitiva de la concesión para los supuestos de infracciones muy graves será acordada por el Consejo de Gobierno de la Junta de Andalucía.

b) Al Director General de Comunicación Social de la Consejería de la Presidencia de la Junta de Andalucía en caso de infracciones graves y leves cometidas por los titulares de la concesión, así como de todas las infracciones, cualquiera sea su calificación, cometidas por razón de la prestación del servicio sin disponer de la concesión administrativa.

2.- Corresponde a la Dirección General de Comunicación Social la competencia para iniciar los procedimientos sancionadores en esa materia.

\section{Artículo 27. La inspección}

Será competencia de la Dirección General de Comunicación Social la inspección y comprobación del cumplimiento de aquello que establece el presente Decreto y el resto de la normativa de aplicación al servicio de televisión por ondas terrestres y de las condiciones particulares de cada concesión.

Disposición transitoria única. Televisiones locales existentes con anterioridad al 1 de enero de 1995.

1.- Los Municipios y personas titulares de emisoras de televisión local por ondas terrestres en funcionamiento con anterioridad al 1 de enero de 1995, tendrán que obtener la concesión administrativa correspondiente participando en el primer proceso que se convoque en aplicación del presente Decreto

2.-. Aquellos titulares que no obtengan concesión en dicha convocatoria, tendrán que cesar necesariamente en sus emisiones en el plazo de ocho meses a partir de la resolución del proceso concesional a que se refiere el apartado anterior.

Disposición final primera. Facultades de desarrollo.

Se autoriza al Consejero de Presidencia para dictar cuantas disposiciones sean precisas para el desarrollo y ejecución de lo previsto en el presente Decreto.

Disposición final segunda. Entrada en vigor.

Este Decreto entrará en vigor el día siguiente al de su publicación en el Boletín Oficial de la Junta de Andalucía. 


\section{ANEXO II}

\section{DOCUMENTACIÓN A PRESENTAR EN LA FASE DE SOLICITUD}

\section{A) COMÚN A TODOS LOS INTERESADOS}

Petición dirigido a la Dirección General de Comunicación Social, manifestando interés en la gestión de una televisión local por ondas terrestres, con indicación del ámbito territorial de cobertura.

\section{B) ESPECIFICA}

\section{B.1) PARA LOS AYUNTAMIENTOS}

Certificación emitida por el Secretario de la Corporación del acuerdo plenario aprobando la gestión del servicio por el Ayuntamiento y la delegación en el Alcalde para formular la solicitud.

\section{B.2) PARA LAS PERSONAS FÍSICAS}

- Copia legalizada del documento nacional de identidad y acreditación del NIF.

\section{B.3) PARA LAS PERSONAS JURÍDICAS PRIVADAS SIN ÁNIMO DE LUCRO: \\ - Copia autorizada de los estatutos vigentes. \\ - Acreditación de su inscripción en el Registro Oficial correspondiente.}

B.4) PARA LAS PERSONAS JURÍDICAS CON ÁNIMO DE LUCRO:

- Copia autorizada de la escritura pública de constitución, debidamente registrada.

- Copia autorizada de la escritura acreditativa de la representación del solicitante.

- Copia legalizada del CIF.

\section{ANEXO II \\ DOCUMENTACIÓN A PRESENTAR EN LA FASE DE ADJUDICACIÓN}

\section{A) PARA LOS AYUNTAMIENTOS}

1.- Escrito del Alcalde-Presidente de la Corporación dirigido a la Dirección General de Comunicación Social, manifestando la voluntad del Ayuntamiento de participar en la fase de adjudicación. 
2.- Informe del Interventor Municipal sobre los siguientes extremos:

a) Certificación resumida del Presupuesto Municipal Ordinario vigente, tanto de ingresos como de gastos.

b) Proyecto de viabilidad que contemple costes, previsión y calendario de inversiones y de su financiación.

3.- Memoria general de la explotación del servicio municipal de televisión, con certificación del Secretario de la Corporación de su aprobación por el pleno de la misma, donde contendrá al menos los siguientes extremos.

a) Plan general de explotación.

b) Objetivos generales de programación, con expresión del tiempo mínimo de emisión y el porcentaje de producción propia.

c) Objetivos socio-culturales de la programación.

4.- Descripción de la infraestructura técnica con la que se pretende prestar el servicio, la cual se adecuará a los parámetros previstos en el pliego de explotación para alcanzar su zona de servicio.

\section{B) PARA LAS PERSONAS FÍSICAS O JURÍDICAS}

1.- Solicitud dirigida a la Dirección General de Comunicación Social, manifestando la voluntad de tomar parte en la fase de adjudicación, mediante participación en el concurso, a tenor de lo previsto en el Pliego de Explotación.

2.- En el caso de que la solicitud se formule por representante, escritura de poder, debidamente bastanteada, de su capacidad al efecto y fotocopia de su documento de identidad.

3.- Relación detallada, en el caso de sociedades, de todas las personas físicas que participen de forma directa o indirecta en ellas con expresión del porcentaje de su participación.

4.- Memoria general de la explotación del servicio, que contendrá al menos los siguientes extremos:

a) Plan general de explotación, con indicación de las inversiones previstas y asignación de recursos para la prestación del servicio.

b) Declaración de compromiso de cumplimiento de los principios reguladores de la televisión local por onda terrestre.

c) Objetivos generales de programación, con expresión del tiempo mínimo de emisión y el porcentaje de producción propia. 
5.- Declaración jurada de tener capacidad para contratar con la Administración de conformidad con lo dispuesto en el artículo 15 de la Ley 13/1995, de 18 de mayo, de Contratos de las Administraciones Públicas, y no hallarse incurso en ninguna de las prohibiciones de contratar previstas en el artículo 20 de la citada Ley.

6.- Descripción de la infraestructura técnica con la que se pretende prestar el servicio, la cual se adecuará a los parámetros previstos en el pliego de explotación para alcanzar su zona de servicio.

7.- Declaración detallada de la participación del titular y, en su caso de los accionistas, en cualquier otro medio de comunicación audiovisual, con indicación del título y porcentaje de la misma.

8.- Certificaciones acreditativas de encontrarse al corriente en el pago de las obligaciones tributarias y de la seguridad social, y, en su caso, de haber sido desembolsado en un cincuenta por ciento el capital social.

9.- Cualquier otra documentación que pueda servir al solicitante para acreditar su idoneidad.

Nota de los editores de ÁMBITOS: Los textos en negrita están recogidos así en el borrador facilitado a esta revista. 